\title{
CORRECTION
}

\section{Correction to: Fatigue Behavior of Welded API 5L X70 Steel Used in Pipelines}

\author{
Şermin Özlem Turhan • Ali Motameni · Rıza Gürbüz
}

Published online: 26 September 2020

(C) ASM International 2020

\section{Correction to:}

J Fail. Anal. and Preven.

https://doi.org/10.1007/s11668-020-00959-x

In the original article Fig. 3 is incorrect. Following is the correct figure.

The original article can be found online at https://doi.org/10.1007/ s11668-020-00959-x.

Ş. Ö. Turhan $(\bowtie) \cdot$ R. Gürbüz Metallurgical and Materials Engineering Department, Middle East Technical University, 06800 Ankara, Turkey

e-mail: sermin.turhan@metu.edu.tr

\section{A. Motameni}

Faculty of Engineering, Middle East Technical University,

06800 Ankara, Turkey 
Fig. 3 Geometry of hourglasstype specimen and the corresponding moment $(M)$ and stress $(\sigma)$ diagrams as a function of the distance $(x)$

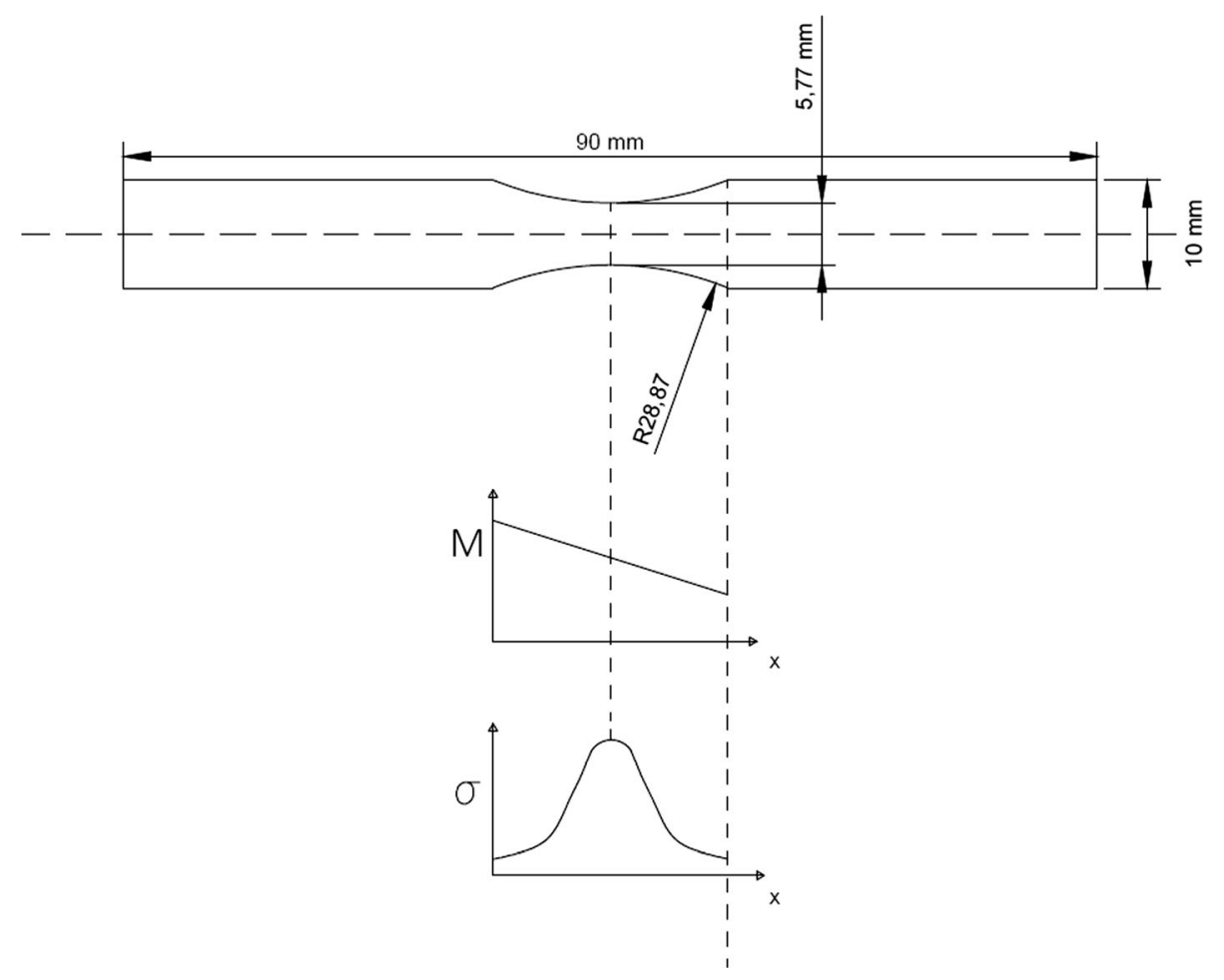

Publisher's Note Springer Nature remains neutral with regard to jurisdictional claims in published maps and institutional affiliations. 